\title{
¿El mundo sería mejor sin dinero? Apuntes desde la historia, la antropología y la economía política en torno a los mercados y las monedas alternativas
}

\author{
Eduardo Enrique Aguilar \\ Universidad Iberoamericana Puebla
}

Resumen

El presente artículo pretende responder al cuestionamiento de qué hacer para que las monedas alternativas no funcionen bajo el paradigma de las monedas de circulación nacional, de manera profunda lo que se está cuestionando, es cómo hacer para que la moneda sea disruptiva al sistema económico dominante, el de la producción capitalista; para poder responder se toman apuntes desde la antropología económica, la historia y la economía política sobre el mercado y las monedas para encontrar su fundamento y con ello visibilizar cuáles son las pautas para que estos espacios puedan ser disputados y llevarlos a una lógica de la reproducción de la vida. Se puede encontrar dentro del presente texto que los mercados históricamente han sido periféricos dentro de la actividad económica humana y que las lógicas reproductivas están basadas en relaciones recíprocas y redistributivas de carácter no mercantil, no obstante, sostenemos que la constitución de mercados y monedas es un primer paso dentro de la construcción de otras economías.

Palabras clave:

Mercado; mercados alternativos; monedas alternativas; reciprocidad, redistribución

Códigos JEL: P26, P50, D40, E50

\author{
WOULD THE WORLD BE BETTER WITHOUT MONEY? NOTES \\ FROM HISTORY, ANTHROPOLOGY AND POLITICAL ECONOMY \\ ABOUT MARKETS AND ALTERNATIVE CURRENCIES
}

\section{Abstract}

The present article aims to answer the question of what to do so that alternative currencies go outside the paradigm of national currency currencies, what is really being questioned is how to make the currency disruptive to the dominant economic system, the capitalist economy; to be able to respond, we bring notes from economic anthropology, history and political economy on the market and currencies to find their foundation and thereby make visible what are the guidelines for these spaces can be disputed and take them to a logic of reproduction of life. You can find within the present text that markets have historically been peripheral to economic human activity and that reproductive logics are based on reciprocal and redistributive relationships of a non-commercial nature, however, we maintain that the constitution of markets and currencies is a first step within the construction of other economies.

Keywords

Market; alternative markets; alternative currencies; reciprocity, redistribution

JEL codes: P26, P50, D40, E50

Fecha de recepción del original: 13 de septiembre de 2018; versión definitiva: 15 de diciembre de 2019.

Eduardo Enrique Aguilar, Profesor de la Universidad de Guadalajara y de la Maestría en Gestión de Empresas de la Economía Social de la Universidad Iberoamericana Puebla; socio-trabajador de la cooperativa Onergia

E-mail: saraivalf@uol.com.br.

ORCID ID: 0000-0002-2393-459X 


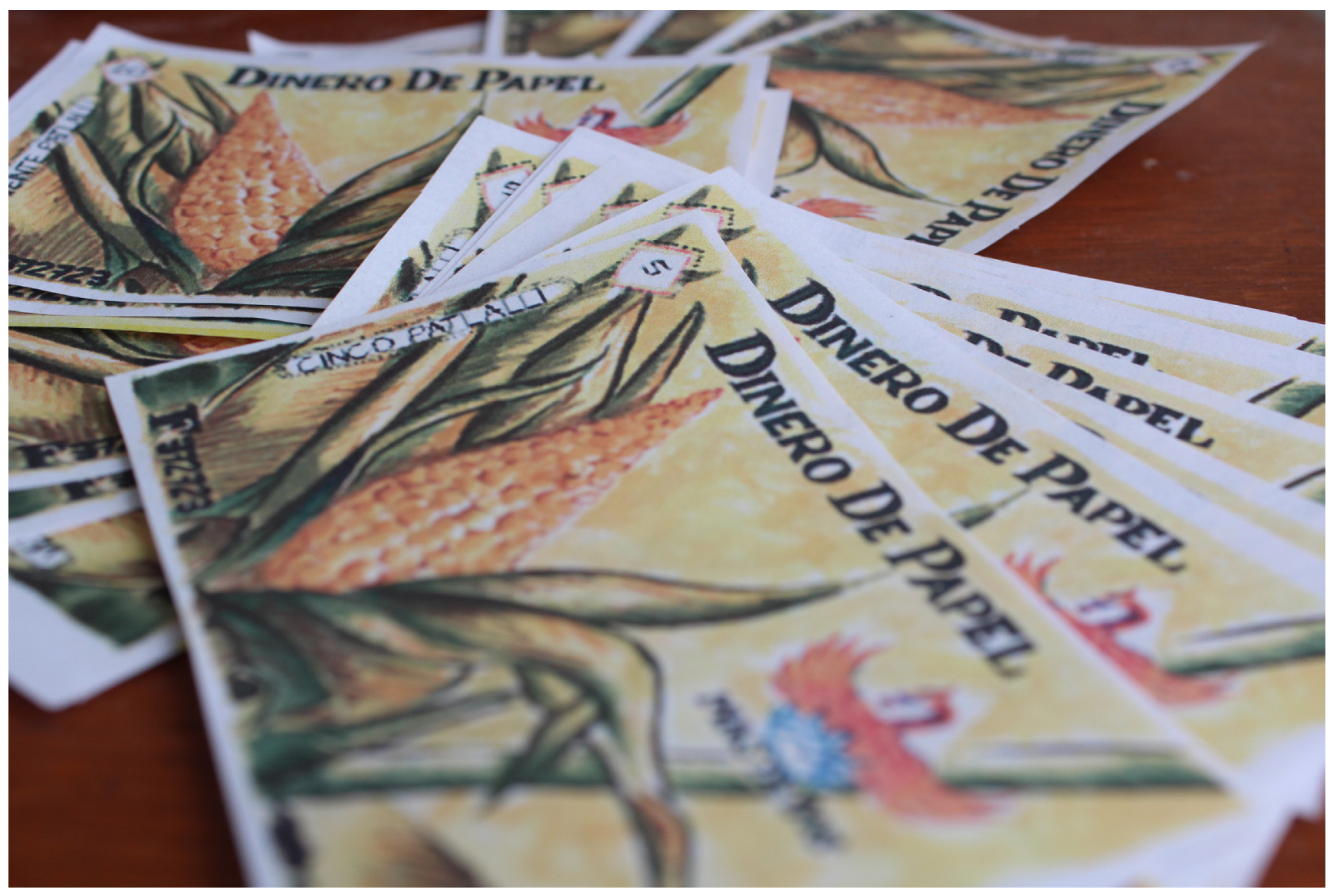




\title{
¿El mundo sería mejor sin dinero? Apuntes desde la historia, la antropología y la economía política en torno a los mercados y las monedas alternativas
}

\author{
Eduardo Enrique Aguilar \\ Universidad Iberoamericana Puebla
}

1. Introducción

El presente artículo nace de la interrogante que coloca Laura Collin dentro del debate de la construcción sobre monedas y dinero alternativo, la autora en su análisis de experiencias mexicanas y argentinas en torno a las monedas sociales lanza una provocación para que reflexionar con cautela,

El problema es cómo crear monedas alternativas que realmente aporten a la generación de riqueza para las comunidades, sin que se conviertan en un instrumento codiciable de poder y por tanto despierten los deseos de incautación por parte del poder o los negocios, o que no se encuentren expuestas a entrar en la misma lógica económica especulativa de la moneda corriente (Collin, 2007: 21).

Tal cuestionamiento lo reflexionamos dentro del "Seminario de Economía Social Solidaria: Producción, Consumo, Circulación y Financiación"1 ${ }^{1}$, donde pudimos esbozar una serie de ideas desde la antropología económica y de la economía política las cuales aquí son presentadas. El artículo está construido de la siguiente manera, en la primera parte recuperamos la noción de reproducción social de un grupo comunitario desde la perspectiva de Bolívar Echeverría y del Seminario de Entramados de lo Comunitario ${ }^{2}$; dichos pensamientos retoman como fundamental para realizar tal acción de reproducción al valor de uso de los bienes producidos, en este sentido enlistamos los dispositivos que han sido funcionales a distintos grupos comunitarios para la circulación de la riqueza socialmente

\footnotetext{
1 Dicho seminario fue realizado dentro del Centro de Estudios del Desarrollo Económico y Social (CEDES) de la Facultad de Economía de la Benemérita Universidad Autónoma de Puebla durante el primer semestre del 2018. Previamente se llevó a cabo otro seminario que titulamos "Economía Solidaria en México" el cual se llevó a cabo el segundo semestre del 2017, dicho evento se realizó en colaboración con profesores de la Universidad de Guadalajara, además en diversas sesiones participaron como invitadas investigadoras/es del COLTLAX, ITESO, UNAM, ECOSUR y UACHiapas. 2 Perteneciente al Instituto de Ciencias Sociales y Humanidades (ICSyH) de la Benemérita Universidad Autónoma de Puebla (BUAP).
}

producida, para esto utilizamos a la historia y a la antropología económica, principalmente a Karl Polanyi; posteriormente, realizamos una revisión de cómo es que el dispositivo de circulación de la riqueza monetario-mercantil, el cual es uno de una gran diversidad, es subsumido por el sistema del capital $y$, generamos la reflexión de los retos para que uno del mismo tipo pero en el ámbito comunitario no caiga preso de la subsunción dentro del sistema dominante, esto tratando de responder la provocación de Collin; finalmente, agregamos unas reflexiones más generales sobre el mercado y el cómo proceder frente a la idea de la transformación de la economía.

\section{Reproducción social de la comunidad}

En primer lugar, tenemos que partir rompiendo con diversas nociones de la naturaleza del ser humano que se han formado dentro de las ciencias occidentales en general y de la economía en particular; sostenemos que no existe un individuo autónomo, autosuficiente, egoísta y un ser con deseos infinitos como sí lo señala la economía (neo)liberal, de manera contraria, existen pruebas antropológicas, arqueológicas y hasta de las neurociencias ${ }^{3}$ que tiran abajo todo el aparato teórico de la ciencia económica dominante. Más bien, la constitución del ser humano históricamente ha sido la de individuos interdependientes, abiertos a la cooperación y con necesidades concretas que al ser cubiertas les permiten prolongar su vida, es decir, sin estos atributos, los seres humanos se acercan a su muerte (Hinkelammert y Mora, 2013; Dussel, 2014).

En este sentido, los conglomerados de sujetos humanos históricamente han tendido redes de cooperación y solidaridad para poder enfrentarse ante un mundo hostil, inclusive ya en la era moderna donde nace la idea de la utilización de la técnica y la mente como forma emancipadora del ser humano

\footnotetext{
3 Para más información sobre estas pruebas remitirse a Hernando (2018), Dussel (2014; 2016), Polanyi (2015), entre otros.
} 
(Villoro, 2010), las redes de interdependencia nunca desaparecieron, la independencia del "hombre nuevo" que surge a partir del renacimiento nunca fue tal, solamente se generaron falsas divisiones entre grupos humanos y de estos con la tierra.

En matrices civilizatorias no occidentales se hace mucho más claro cómo es que la reproducción social responde a la lógica de cooperación y solidaridad. Estas relaciones tienen representaciones simbólicas y materiales la cuales son culturalmente definidas y varían dependiendo de cada contexto e historias, no obstante, dentro de las mismas se pueden encontrar patrones que permiten dilucidar semejanzas y realizar abstracciones para comprender el funcionamiento de la misma reproducción social.

Entonces, como hemos sostenido, la especie humana está conformada por sujetos con necesidades concretas materiales e inmateriales, las cuales precisan ser satisfechas para reproducir la vida, si hacemos un análisis específicamente dentro del ámbito material, para cubrir las necesidades materiales vemos que precisa consumir elementos de la naturaleza exterior a la humana, estos elementos se convierten en satisfactores de diversa índole cuando se le incorpora trabajo, a esta relación entre seres humanos (siempre bajo un tipo de socialidad) y de los seres humanos con la naturaleza, se le considera como metabolismo social y se puede entender como el cúmulo de relaciones básicas y fundamentales para la constante actualización de la vida. La humanidad por muchas generaciones ha vivido bajo esquemas metabólicos equilibrados consumiendo productos de su trabajo los cuales cuentan con características culturalmente definidas las cuales son funcionales al mismo grupo humano para su reproducción, en este sentido, los productos-del-trabajo se convierten en bienes que reproducen o afirman la vida.

Lo cierto es que estos bienes nunca se producen por individuos autónomos, siempre se han creado bajo esquemas sociales definidos, aunque existen productores individuales la producción siempre ha sido bajo el esquema de la reproducción de los núcleos humanos (más contemporáneamente considerados como unidades domésticas). Así, históricamente los bienes no se han producido para la acumulación sino para el goce del grupo en general, el cual afirma la vida de cada ente particular que conforma el conglomerado humano. La riqueza, es efectivamente, el goce de dicho bien (García, 2015). Por tanto, la producción de bienes siempre es social y la riqueza, históricamente, también lo ha sido; es solo hasta la época moderna donde la riqueza se convierte en privada o para disfrute exclusivo. Una de las grandes claves para asegurar el carácter social de la riqueza es la consolidación de la producción y el consumo común, de ahí que la clave de lo comunitario sea tan relevante; históricamente los conglomerados humanos crearon el símbolo de lo común como una de las bases de afirmación de la vida del colectivo, el trabajo en común da como un resultado bienes comunes ${ }^{4}$.

\footnotetext{
${ }^{4}$ Se puede rescatar esta concepción sobre este tipo de bienes "están cargados de fines para satisfacer necesidades biológicas y culturales a través del consumo individual y colectivo - de la materialidad misma- [...] tales bienes comunitarios también tienen el fin de satisfacer las necesidades de otros a partir de la propia trama de sentido que generan -dimensión semiótica de la cultura- por lo cual son 'objetos' que están dotados de sentido más allá del valor de cambio" (Gutiérrez y Salazar, 2015
}

En este momento, se precisa señalar algo que ya se había tomado en los párrafos anteriores, y es el hecho de que los bienes son culturalmente definidos, por tanto, no son universales, en otras palabras, un producto-de-trabajo puede ser un bien dentro de un grupo humano pero puede que no lo sea dentro de otro grupo humano con características simbólico-culturales diferentes. La característica esencial de un bien es el valor de uso, el cual lo podemos comprender como una intersubjetivación que dota a un producto-de-trabajo de una connotación positiva para la afirmación y reproducción de la vida, es decir, el producto se convierte en bien porque cuenta con una utilidad concreta la cual, específicamente, se mide en función de cubrir con una necesidad concreta ${ }^{5}$.

Entonces materialmente, la reproducción del conglomerado social, específicamente del comunitario, se ha dado a través de la producción y el consumo de los productos de trabajo común lo cual genera del mismo modo riqueza común, en este sentido, ya nos podemos acercar a revisar cómo es que dicha riqueza ha sido circulada entre todos aquellos involucrados dentro del conglomerado social para poder afirmar y reproducir la vida del grupo, en otras palabras, precisamos reconocer aquellos dispositivos de circulación de la riqueza socialmente producida.

\section{Circulación de la riqueza socialmente producida}

Los seres humanos han utilizado una serie de dispositivos que han permitido la circulación de la riqueza socialmente producida, estos dispositivos presentan una serie de patrones que la corriente de la antropología económica ha visibilizado, específicamente retomaremos la propuesta de conceptualización de Karl Polanyi, este autor señala que dentro de la esfera económica de la circulación los grupos humanos han contado con tres principios fundamentales los cuales han permitido la reproducción del colectivo.

El primer principio que se enuncia es el de la reciprocidad, el cual sostiene que "ayuda a salvaguardar la producción y el sostenimiento familiar" (Polanyi, 2015: 96), y tiene que ver con la capacidad del ofrecimiento de los bienes, dicho ofrecimiento es polimorfo, no cuenta con una estructura particular ni con un tiempo y espacio definido, por tanto, puede ser un ejercicio de don y contra-don, también puede ser solamente una acción

\footnotetext{
33-34).

${ }^{5}$ En palabras de Bolívar Echeverría, "[es] una porción de materia concretamente útil o con valor de uso: un bien. Y no solamente un bien en general -definido de manera puramente natural-, sino un bien culturalmente específico o un elemento que pertenece diferencialmente a la totalidad sistemática de lo que es efectivamente bueno o favorable para satisfacer las necesidades de consumo -en unos casos final o disfrutante, en otros intermedio o productivo- de un determinado sujeto social. Pero no es solamente un bien; es también, desde una segunda perspectiva, complementaria de la primera, un producto, una materia cuya utilidad es producida o ha resultado de un trabajo de transformación sobre otra materia. Y tampoco es un producto general -definido solo de manera utilitaria-; es un producto culturalmente específico" (Echeverría, 2017: 108)
} 
de don sin esperar nada a cambio o viceversa, recibir sin ofrecer, inclusive puede existir una reciprocidad negativa como la que se caracteriza en la venganza o en el robo. La reciprocidad definitivamente no se puede reducir a un intercambio de bienes, este ha sido un error que ha llevado a confusiones en la concepción disruptiva de la reciprocidad ${ }^{6}$. Desde la concepción de Polanyi, dicho principio necesita el patrón institucional de la simetría entre individuos ya que sin esta los flujos recíprocos encontraría trabas e inclusive la dinámica cambiaría, por ejemplo, ante una falta simetría la relación pasaría de ser recíproca a ser de dependencia como en las de la filantropía o del clientelismo. El rasgo principal de la simetría es que históricamente ha tenido fundamento en los lazos familiares o de parentesco así como religiosos o místicos, el arroparse bajo estas lógicas culturales funciona, entre otras cosas, como una justificación de la circulación de la riqueza para la afirmación de la vida del colectivo.

El segundo principio es el de la redistribución, el cual precisa del patrón institucional de la centralidad, es decir, la concentración de la riqueza social para que posteriormente pueda ser entregada con reglas particulares a los demás sujetos del conglomerado social, "el patrón institucional de la centralidad, que está presente en alguna medida en todos los grupos humanos, provee un procedimiento para la recolección, el almacenamiento y la redistribución de bienes y servicios" (Polanyi, 2015:97); de igual manera que la reciprocidad, este principio funciona bajo formas culturales específicas, y aquí la potestad que es otorgada a un miembro del conglomerado humano para poder redistribuir los bienes se da por lo general por cuestiones de míticas (Wolf, 2001), de prestigio (Álvarez, 2012) o religiosas (Polanyi, 2015), entre algunas otras. Desde el pensamiento de Semo (2006) el principio de redistribución se comienza a dar desde el crecimiento de la cantidad de individuos de los grupos humanos y la forma sedentaria de los mismos al desarrollar ciertas habilidades de agricultura.

Y finalmente, Polanyi enuncia el principio de la autarquía, el cual nosotros lo entendemos como autoconsumo pues creemos que la autarquía total en la unidad doméstico o grupo familiar genera una pérdida de la diversidad. Según estas corrientes de la antropología económica, dichos dispositivos de circulación de bienes existieron de manera predominante a lo largo de la historia de la humanidad. Cabe destacar también que podemos recuperar ciertos rasgos comunes dentro de estos principios económicos, que enunciamos de la siguiente manera: (i) son meramente cualitativos al otorgarle valor a los bienes por la manera en que afirman la vida $y$, por tanto, por su goce o consumo, dentro de estos mecanismos ninguna manera los bienes producidos son cuantificados o medidos con respecto a algún parámetro que no sea el de la utilidad para cubrir las necesidades corporales concretas; (ii) fomentan una constante interrelación humana, en otras palabras, al tener como objetivo principal la reproducción del grupo humano lo

\footnotetext{
6 En palabras de Sabourin, "el reduccionismo de esa definición [dar y recibir], que por mucho tiempo prevaleció en la antropología, conduce a una confusión entre trueque [intercambio] simétrico y reciprocidad. Ese impasse persistirá, mientras que la reciprocidad sea interpretada con la lógica binaria que conviene al trueque. El trueque puede reducirse, al límite, a un intercambio de objetos" (Sabourin, 2011: 30)
}

que se fomenta es una relación con el otro, los bienes quedan en segundo término siendo solo el instrumento para fomentan la permanencia de un vínculo social?.

En este sentido, no se ha comprobado históricamente una propensión natural del individuo social a trocar, es decir, a intercambiar unos bienes por otros. Este hecho mercantil, aunque hay pruebas de su existencia desde la edad de piedra, no ha sido más que incidental y periférico, no ha sido utilizado como forma económica primordial para la circulación de la riqueza socialmente producida hasta el advenimiento y posicionamiento hegemónico del sistema de producción capitalista. Dentro de las muestras antropológicas se puede comprender que la utilización de una lógica mercantil fue mucho más ritualista y para la obtención de bienes que podrían llamarse suntuarios, estos objetos claramente no cuentan con la razón, en sentido estricto, de reproducción y afirmación de la vida del conglomerado humano sino para mantener diversos tipos de contacto con grupos humanos ajenos, lejanos o de matrices culturales diferentes, si bien existen excepciones, se constata que este fue el patrón social.

¿Tiene sentido que la forma mercantil no haya sido incorporada como básica para la reproducción y afirmación de la vida de los grupos humanos? Sostenemos que sí desde que la relación de mercado y su patrón institucional de intercambio cuenta con características que generan dislocaciones de las relaciones sociales funcionales al objetivo de reproducción. Como señala Echeverría, "[a] diferencia del principio distributivo comunitario, el principio mercantil es 'cósico' y no sujetivo, 'casual' y no necesario (voluntario)" (Echeverría, 2017: 126), en otras palabras, son rasgos contrarios a aquellos encontrados dentro de los principios de reciprocidad, redistribución y autoconsumo. Cuando este autor señala que es "cósico y no sujetivo", se está refiriendo a que lo que prima ya no es el fomento de la permanencia del vínculo humano, más bien la relación social sufre un proceso reduccionista al objetivarla en dar/recibir un bien, esto se hace claro cuando el intercambio queda "pagado", es decir, al recibir un bien y otorgar otro que le sea equivalente las necesidades quedan satisfechas por lo que no se hace necesario mantener un vínculo; esta idea está muy ligada a la siguiente conceptualización de "casual y no necesario (voluntario)" pues al no contar más con la obligatoriedad subjetiva que generan los vínculos humanos se da la posibilidad de la no asistencia al mercado, este hecho puede generar la situación de imposibilidad de acceso a un bien necesario al grupo social, dicha situación es radicalmente contraria a la lógica de reciprocidad y redistribución donde se tiene acceso a los bienes necesarios pues la lógica es el mantenimiento del grupo.

Históricamente la obligatoriedad de ingresar a la lógica mercantil rompió con la lógica comunitaria, como habíamos visto la lógica de lo comunitario precisa de la producción y el consumo común, por tanto, la circulación de los bienes producidos es social (bienes comunes); dentro del mercado la

\footnotetext{
7 Recuperamos la noción directa de Polanyi, "El hombre no actúa para salvaguarda sus intereses individuales en la posesión de bienes materiales, sino para salvaguardar su posición social, sus derechos sociales, sus activos sociales. El hombre valúa los bienes materiales solo en la medida en que sirvan a este fin" (Polanyi, 2015: 94).
} 
producción pasa a ser del ámbito privado la cual es requisito para poder valuar el trabajo de un productor frente al trabajo del otro ${ }^{8}$ y posteriormente buscar equivalencias entre los bienes para poder ser intercambiados, la acción de darle equivalencias a los bienes no es un hecho natural, para poder llegar hasta ahí se ha tenido que generar la noción de un valor de cambio, es decir, valorizar al bien bajo una visión diferente a la de su utilidad para afirmar la vida (cubrir una necesidad concreta de la corporalidad humana), esto indudablemente es una reducción de todas las dimensiones de un producto-detrabajo humano.

El otorgar un valor de cambio es una construcción social que ha pasado por diversas transformaciones a lo largo de la historia y está sujeta a muchas regulaciones, por ejemplo, dicho valor de cambio puede ser determinada por un Estado o puede ser contabilizada por el tiempo de trabajo que se necesitó para producir el bien, no obstante, la forma que se torna general dentro del establecimiento del valor de cambio se da dentro del juego de la oferta y demanda de bienes puestos dentro de los intercambios mercantiles, es decir, el valor es relativo frente a la cantidad de trabajo que se presenta frente a otros tipos de trabajo (Echeverría, 2017: 132); así, si muchos propietarios privados ofertan una gran cantidad de bienes de un tipo (mayor cantidad de trabajo) y en el mismo espacio se presentan una cantidad muy reducida de otro tipo de bienes (menor cantidad de trabajo), y ambos tipos son necesarios para la reproducción de la vida de todo el colectivo social, a los primeros bienes se les asignará una cantidad de valor menor que al segundo tipo ${ }^{9}$. Es importante indicar que, al alejar al bien de su función principal que es el de la afirmación de la vida, se le dota al mismo de un carácter de extrañeza y de enajenación, pues ahora el carácter de intercambiabilidad genera una primacía del valor de cambio de valor de uso (utilidad concreta) del bien.

Recapitulando la idea, la historia nos ha mostrado que la reproducción de los diversos conglomerados sociales se ha realizado mediante autoconsumo, las relaciones de reciprocidad y las de redistribución; estas lógicas no han desaparecido hoy en día, tanto en ámbitos urbanos como en rurales permanecen y son funcionales a la reproducción social, asimismo estos principios de circulación de bienes no son puros y coexisten en diferentes niveles y escalas; no obstante, desde el advenimiento hegemónico del sistema de producción capitalista se ha impuesto una forma de circulación que no es funcional a la reproducción social pero sí para la acumulación del capital, la forma mercantil, la cual tiene características que rompen con la lógica de circulación comunitaria de bienes al separar ficticiamente a los individuos en productores privados para

\footnotetext{
8 Retomando las palabras de Echeverría, “[l]a circulación con base en el trueque o intercambio constituye el único campo de socialización efectiva de los individuos sociales en tanto que propietarios privados; éstos solo existen socialmente en virtud de que existen para el trueque o tienen algo que ofrecer a cambio de lo que necesitan" (Echeverría, 2017: 128); concretamente, si el trabajo es social y se producen bienes comunes con dicho trabajo, entonces la relación de valuación de estos para su intercambio resulta ser incomprensible.

${ }^{9}$ Como se comenzó señalando, existen diversos aspectos que distorsionan esta asignación de valor basada en la escasez, por ejemplo, la renta tecnológica (2005) o la renta de espectáculos permiten que exista una sobrevaluación de ciertos bienes o servicios.
}

que, de esa manera, puedan valuar sus productos-de-trabajo y darles la característica de intercambiabilidad.

No obstante, la imposición del mercado dentro de la sociedad global no ha sido homogénea, de hecho, existen diversos movimientos que reivindican este espacio como forma de resistencia y lucha, sostenemos que si realmente se pretende utilizar de manera subversiva se precisa de conocer qué elementos son realmente disruptivos, de esto se tratan los dos siguientes apartados.

\section{Expansión del mercado por la ideología liberal}

Como lo hemos venido señalando, para que una lógica mercantil funcione precisa de la intercambiabilidad de bienes, esta característica permite la troca de los mismos a través de las equivalencias, así tiene sentido el hecho de que productos de muy distinta índole y con diferentes tipos de materiales y esfuerzos humanos puedan ser comparados y cambiados de manos; no obstante, aún ya con la noción de intercambiabilidad la circulación mediante trueque es ineficiente ${ }^{10}$ por lo que se precisó incorporar a la lógica un instrumento que facilitara los intercambios, es decir, un objeto que fungiera como equivalente general. Dicho equivalente, ha tenido diferentes manifestaciones dependiendo de los contextos culturales y ambientales, así han sido desde conchas de mar, cacao, lienzos de tela, papel, así como metales preciosos. Como fue indicado previamente, la lógica mercantil y, por tanto, la noción de poder intercambiar unos bienes por otros, se dio de manera exógena a los conglomerados humanos, y era utilizado en alguna medida como de comercio exterior, es decir, de obtención de bienes con grupos humanos con los cuales no se compartía el trabajo común y por tanto, no podría haber usufructo de bienes de manera comunitaria, en este aspecto, había una lógica social de acercamiento y diálogo entre pueblos ${ }^{11}$, en esta dinámica, los equivalentes generales eran multiformes.

Pero en la época moderna, a partir del siglo XVIII y particularmente dentro del siglo XIX con el nacimiento y consolidación de la ideología liberal hubo sistemáticamente una serie de esfuerzos por la instauración del mercado como sistema dominante en el ámbito económico pues se creía (y se sigue teniendo la falsa idea) que un mercado autorregulador era la mejor forma que los individuos podrían lograr el mayor nivel de bienestar, si bien esto es algo totalmente fuera de la realidad, lograron su objetivo, separaron la esfera económica de las relaciones sociales.

\footnotetext{
${ }^{10}$ Como se señaló, la relación mercantil es voluntaria y cósica.

11 A lo largo de la historia vemos que la lógica mercantil no ha sido unitaria, en Polanyi (2015) y todos los antropólogos que rescata como Mauss, la lógica es más bien amistosa dentro de los grupos que ellos estudian; Wolf (2001) señala que en ciertos grupos también tiene que ver con una lógica cósmica; por su parte Semo (2006) indica que también se abrieron mercados bajo una lógica entre grupos que se obligaron a comerciar ya sea para mantener relaciones de paz o porque unos conquistaron militarmente a otros.
} 
Con el devenir del mercado y su imposición dentro de las matrices civilizatorias no occidentales alrededor del mundo se fueron homogenizando y normalizando las prácticas de intercambio, de esa manera los bienes podrían fluir entre fronteras, dicho movimiento internacional de comercio fue (y sigue siendo) a costa del quebranto de las relaciones de autosuficiencia y de reciprocidad. Aquí es importante señalar que para que se haya podido generalizar el movimiento e intercambio internacional se impuso el patrón oro como equivalente general, así todos los nuevos mercados que fueron creados y expandidos podían intercambiar los bienes que eran producidos.

Estos movimientos que se expanden bajo las ideas liberales fueron promovidas por las nuevas clases que se veían beneficiadas por el pujante sistema capitalista, claramente el mercado al sobreponer el valor de cambio sobre el valor de uso se hace ideal para que cierta parte del valor de cambio sea apropiada por el grupo de personas "que controlan y usufructúan del trabajo de otros" (Gutiérrez, 2009:43). En otras palabras, el mercado en general, es el espacio privilegiado para poder generar dislocaciones sociales que desgarran a la sociedad en individuos productores privados; en específico, el mercado capitalista hace que dentro del desgarramiento social, un grupo pueda apropiarse de una cantidad de valor la cual han tendido a acumular hasta ver la gran desigualdad existente al día de hoy.

En este sentido, la moneda no ha sido un componente neutral, fue subsumida por el sistema de producción capitalista para ser funcional a su lógica, la misma moneda fue convertida en una mercancía, característica que no se vio dentro de los sistemas mercantiles previos, de hecho, la misma moneda contaba con otras características físicas, por ejemplo, tener una finitud de tiempo de existencia, tal cual, una concha de mar o un grano de cacao no cuentan con la particularidad de contar con un tiempo largo de vida pues la concha se quiebra y el cacao es biodegradable, la razón de la utilización de la moneda en aquellos sistemas mercantiles era sumamente distinta a la creada y forzada por el sistema de mercado capitalista. Esta es una pauta que nos permite dar luz a la constitución actual de mercados alternativos, es decir, abre una ventana para comprender que hasta dentro del mismo sistema de mercado puede existir una disputa, que aunque dicha forma de circulación de la riqueza social no tiene sentido para crear relaciones de producción comunitaria, sí es un paso para cambiar el sentido de la economía al tener la posibilidad de que no exista apropiación del trabajo por unos pocos, en otras palabras, existe la posibilidad real de recuperar un mercado para que dentro del intercambio de bienes prime la valía-social comercial simple y no la valía-social comercial capitalista ${ }^{12}$

\footnotetext{
12 Dentro de las relaciones mercantiles, Echeverría (2017) distingue las relaciones mercantiles simples y las relaciones mercantiles capitalistas, las primeras se dan en tre individuos que son propietarios de sus medios de producción y solo buscan el intercambio de sus productos-de-trabajo, dentro de las segundas, ya están inserta la búsqueda de la apropiación de la plusvalía.
}

\section{El reto de la no subsunción}

Creemos que es un reto de mantener alejada a la moneda y los mercados lejos de la lógica económica del modelo capitalista; efectivamente como hemos señalado el mercado tiene una gran contradicción que es difuminar el valor de los bienes al reducirlo solamente a su valor de cambio, esta es una contradicción insalvable que se genera por la necesidad del intercambio y una de las llaves para que sea funcional al sistema de producción capitalista; no obstante a esto, y solamente mientras se constituyen y fortalecen relaciones comunitarias (que sufren de constantes ataques) y de sus formas particulares de circulación de la riqueza socialmente producida, tenemos claro que se precisa disputar los mercados en su esencia no capitalista, es decir, mantener los intercambios de bienes en bajo una valía-social comercial simple (sin búsqueda de plusvalor), por tanto, presentamos una especie de decálogo, que sin ser una guía estricta, sí nos ayudan a repensar las relaciones mercantiles desde la perspectiva de una sociedad comercial simple.

\subsection{A nivel mercado}

1. Propietarios privados que sean dueños de sus medios de producción. Desde la perspectiva de Echeverría (2017), una de las características del mercado capitalista es que en este se pueden encontrar la mercancía de fuerza de trabajo y la que es propiamente capital ${ }^{13}$, en una relación tensa de intercambio los que ofrecen el capital terminan apropiándose de una parte del trabajo de aquellos que se ofrecen su corporalidad a la venta. Efectivamente, para poder romper con esta lógica, los productores privados precisan concurrir al mercado no para ofrecer su corporalidad viviente sino para ofrecer sus productos de trabajo, esta relación si bien es cósica y voluntaria no es a priori una relación desigual entre los individuos, la única desigualdad se presentará frente a la cantidad de productosde-trabajo presentados para intercambiar así como de las necesidades que sus bienes cubren.

2. Romper con las mercancías ficticias. Yendo más allá de Echeverría, se hace preciso recuperar el aporte de Polanyi (2015) al señalar que el mercado que es funcional al sistema de producción capitalista es aquel donde se presentan a la mano de obra, la tierra y el dinero como mercancías; si bien dentro del punto anterior abordamos a la fuerza de trabajo

\footnotetext{
13 En las palabras de Echeverría, “[u]na sola característica distingue en lo fundamental la esfera de la circulación mercantil capitalista de la que es simplemente mercantil. Mientras en esta última todas las mercancías que la 'habitan' poseen una figura elemental uniforme, en aquellas coexisten en relación complementariedad y conflicto, mercancías de dos figuras complejas claramente distintas: las mercancías que son fuerza de trabajo y las que son propiamente capital" (Echeverría, 2017: 136).
} 
(que es otro nombre a la mano de obra) establecemos categóricamente que un humano no puede ser reducido solamente a ser mano de obra ${ }^{14}$; tampoco la tierra puede ser reducida a mercancía por el simple hecho de que la naturaleza no puede comprarse y venderse sin generar una dislocación radical de su funcionamiento; finalmente, el dinero se le coloca falsamente como mercancía para convertirlo en un instrumento que facilite no solo el intercambio de bienes sino la especulación y la acumulación.

3. Asignación de precio. La asignación de precio dentro de la lógica mercantil está regulada a través de la ley de oferta y de demanda frente a un escenario de escasez, el hecho de subir el precio a un producto-de-trabajo no equivale directamente a decir que existe un precio justo, los precios siempre serán injustos no por la cantidad que representen sino por el hecho de que el producto-de-trabajo humano sea valuado cuantitativamente; este hecho se ve mucho más claro cuando el bien es intangible, si ejemplificamos con la asignación de precios dentro de los servicios se disparan una serie de cuestionamiento cuya respuesta resulta ser compleja ¿cuál es el precio de una consulta médica? ¿el precio del tiempo de los músicos? ¿el costo de un poema? ¿el costo de la preparación de un platillo de comida? Esto deviene peor cuando el trabajo es invisibilizado y no es remunerado ¿cuál es el valor del cuidado de los hijos o de los ancianos? ¿cuánto vale la limpieza del hogar? ${ }^{15}$ Efectivamente, lo que podemos concluir es no existe justicia en el mecanismo de precios, lo máximo que se puede lograr es que la cantidad de monedas entregadas (en su forma de equivalente general) sean las suficientes para que el propietario privado pueda conseguir la cantidad de bienes para la reproducción de su vida de la forma más digna posible.

\footnotetext{
14 En palabras de Polanyi, “[e]l trabajo es solo otro nombre para una actividad humana que va unida a la vida misma, la que a su vez no se produce para la venta sino por razones enteramente diferentes; ni se puede separarse esa actividad del resto de la vida, almacenarse o movilizarse [...] Si se permitiera que el mecanismo del mercado fuese el único director del destino de los seres humanos y de su entorno natural incluso de la cantidad y el uso del poder de compra, se demolería la sociedad. La supuesta mercancía llamada 'fuerza de trabajo' no puede ser manipulada, usada indiscriminadamente, o incluso dejarse ociosa, sin afectar también al individuo humano que sea el poseedor de esa mercancía peculiar. Al disponer de la fuerza de trabajo de un hombre, el sistema dispondría incidentalmente de la entidad física, psicológica y moral que es el 'hombre' al que se aplica ese título" (Polanyi, 2014: 123); al respecto, Dussel (2014) lo señala como trabajo alienado a aquel que es inserto a la lógica mercantil, para este autor el trabajo que realiza un sujeto es un trabajo vivo y este es fuente de todo valor, crea el valor y por tanto no puede tener ningún precio.

15 Dentro de las lógicas de economía alternativa tampoco ha habido una respuesta que satisfaga; el teórico brasileño Euclides André Mance es uno de los pocos que dentro del área de la economía solidaria se ha lanzado a realizar una de las más interesantes sistematizaciones y propuestas concretas poscapitalistas a la que ha llamado redes de colaboración solidaria, su propuesta, como ejercicio de economía política, se ve bastante sólida cuando problematiza el papel de los excedentes dentro de la lógica productiva donde señala que se precisan de disputarle al capital utilizarlos para la constitución de nuevas células productivas, empero, flaquea cuando se trata de revisar la misma metodología con respecto a los servicios pues él mismo no puede valorarlos justamente; cuando se le ha cuestionado al respecto no ha podido esgrimir una respuesta contundente y más bien ha terminado cambiando el rumbo de su respuesta, esto ha acontecido en dos ocasiones, la primera en el seminario "Economía y redes solidarias" del 9-11 de febrero de 2015 en el CEDES-BUAP y la se gunda en el 1er Encuentro de la Economía Solidaria y la Economía Azul realizado el 18 y 19 de abril en Ciudad de México.
}

\subsection{A nivel moneda}

1. No acumulación. La lógica monetaria precisa de una revisión más detallada para problematizar el proceso de acumulación, pues bien se sabe que toda acumulación de dinero no es capital ni responde a su lógica de "valor que se valoriza" o de tendencia creciente de valorización; ¿será que podemos contar con una acumulación solidaria, creemos que sí, y que de hecho es necesaria para poder entrar en la disputa en contra del capital ${ }^{16}$, la necesitamos para poder conseguir los medios de producción necesarios para generar una vida digna, creemos que aquí es donde entra el papel de las finanzas solidarias pero es un tema en el que no podemos abundar más; entonces sostenemos que cuando hablamos de la no acumulación de la moneda alternativa nos referimos a que es necesario que no ingrese en la idea de que la acumulación es el fin y no el medio. Cuando una moneda comienza a ser medio de acumulación para generar mayor acumulación entonces se rompe el sentido de lo alternativo.

2. Representante de trabajo real. Uno de los grandes problemas de las monedas convencionales es que no representan el trabajo real sino uno valor ficticio que está más ligado a la especulación y la valorización ilimitada, por tanto, la moneda alternativa debe de representar el trabajo realmente existente que debe de circular entre los concurrentes, caso de no hacerlo se ve supeditado a fluctuaciones y desequilibrios que afectan al mercado y, por tanto, a aquellos que asisten al mismo.

3. Temporalidad - emisión/oxidación. Este está muy ligado al punto anterior, pues es la capacidad de la moneda de dejar de funcionar cuando no sea necesaria, un caso es el de la moneda ferial ${ }^{17}$, la cual solo circula mediante un lapso predeterminado de tiempo y deja de funcionar; por otra parte, y ligándolo con el punto anterior, la moneda social tiene que contar con la capacidad de aumentar su masa o disminuirla según la cantidad de bienes presentados dentro del mercado, a estos procesos los llamamos de emisión u oxidación según sea el caso.

4. No interés. La moneda no puede tener un interés, según lo que hemos expuesto, tiene que ser un instrumento con carácter de equivalente general por lo que su valor es socialmente colocado la finalidad de generar la circulación y no obtener una ganancia.

5. Convención y regulación social. Como se mencionó, el valor de la moneda como equivalente se coloca mediante un diálogo entre los concurrentes, estos establecen los términos de intercambio, en este sentido, también el instrumento queda bajo la supervisión de los concurrentes, el colectivo se hace cargo de que se cumpla el funcionamiento propuesto por todos, en más de alguna experiencia esta tarea se delega a un

\footnotetext{
16 Antônio Cruz (2011) hace un desplegado sobre la necesidad de la acumulación solidaria en términos mucho más amplios de lo que exponemos aquí.

17 El caso más representativo en México es la Feria Nacional Vida Digna donde utilizan una moneda ferial llamada mezquita, para más información ver: http://redtlaloc.blogspot.com/2013/07/invitacion-la-feria-nacional-vida-digna.html (revisado 06 septiembre 2018).
} 
pequeño grupo, el cual muchas veces también funge como emisor de la moneda ${ }^{18}$.

6. Exclusividad (no complementaria). Conforme lo que se ha expuesto en los puntos anteriores, podemos señalar que coincidimos con lo expuesto por Collin al referirse en que la moneda alternativa no debe de ser complementaria, ya que al ser una convención social para la circulación de los bienes presentados en un mercado, al complementarla con moneda nacional se generan diversas consecuencias que rompen la lógica planteada ${ }^{19}$

Si bien, creemos que estas son claves fundamentales para que la moneda se mantenga fuera del sistema de acumulación capitalista, señalamos que no es suficiente, es demasiado pretensioso pensar que con tan solo cambiar al mercado y la moneda ${ }^{20}$ sin ligar un cambio estructural dentro de las demás esferas económicas (producción, consumo, financiación) se puede generar una economía alternativa. Efectivamente, este instrumento tiene relevancia pero carece de un sentido disruptivo si no se le asocia directamente con las otras formas cualitativas de circulación de bienes.

\section{Reflexiones finales}

Una reflexión importante que se precisa dejar plasmada es sobre la distinción de lo mercantil, esto no es menor, ciertamente el mercado ha sido utilizado durante diversas etapas de la humanidad, empero, este no es un argumento para defenderlo, sobre todo, si es que existe la intención de construir otra economía. Las relaciones mercantiles fuera de la matriz civilizatoria moderno occidental se diferencian sustancialmente de las relaciones mercantiles contemporáneas; aquellos mercados no moderno-occidentales se desenvolvieron como espacios como externos, periféricos, mucho más como un actos simbólicos-culturales que para la obtención de los bienes

\footnotetext{
18 En 2015 organizamos dentro del Centro de Estudios del Desarrollo Económico y Social (BUAP), un ejercicio de moneda social con diversos productores de la región donde se le asignó a un pequeño grupo de personas la emisión de la moneda así como la vigilancia del funcionamiento, más información ver: https://ladobe com.mx/2015/11/moneda-comunitaria-una-alternativa-de-consumo-local, también https://www.lacoperacha.org.mx/surge-patlalli-moneda-social-buap.php (revisados 06 de septiembre de 2018)

19 Laura Collin señala dos consecuencias negativas que resultan del complementar la moneda alternativa con la moneda de curso nacional legal, la primera a nive epistemológico-simbólico y podría añadir pedagógico, "[la moneda alternativa] es un acuerdo dentro de una comunidad para utilizar algo como medio de pago, si esta aparece como complemento, no se visualiza el acuerdo, sino que se sigue privando el acuerdo previo con el dinero de curso corriente. Por tanto, no opera la confianza como sustrato de la relación, confianza implícita en la aceptación de otro medio de valor, solo se utiliza como forma de promoción"; asimismo, menciona otro nivel, "a nivel fáctico, se propicia el se propicia el establecimiento de precios en pesos [moneda nacional] y que la parte en moneda alternativa constituya nada más un sobreprecio si la parte del intercambio en moneda alternativa corresponde a un sobreprecio, no se intercambia nada [...] y por ende no propicia relaciones de confianza, como es objetivo" (Collin, 2007: 20).

20 Como señalamos, el mercado es un subconjunto de relaciones de la parte equivalencial (donde prima el valor de cambio) de todo el entramado de la esfera de la circulación
}

para la reproducción; por otra parte, el mercado actual (tiene la pretensión) de regir toda la actividad humana, primero cosificando y luego mercantilizando, dicho proceso se da a través de un despojo material y de destrucción cultural de modos de vida ajenos a esta lógica.

El movimiento social o presencia colectiva que se dispone a disputar el mercado actual o salirse de él constituyendo mercados alternativos se tendría que considerar que este es solo un movimiento táctico y nunca un lugar a llegar u horizonte por conquistar, en otras palabras, la lucha por la constitución y uso de los mercados y monedas alternativas es tan solo una etapa de aprovisionamiento para fortalecer las capacidades productivas de los entes autogestivos (principio autárquico/ autoconsumo) para posteriormente desbordar la democracia interna de dichos entes para realizar acuerdos políticos con otras entidades semejantes, este hecho paulatinamente debería culminar en procesos de reciprocidad y redistribución para la circulación de los bienes que se encuentran produciendo.

Bibliografía

ÁLVAREZ, J. (2012): "La economía comunitaria de reciprocidad en el nuevo contexto de la Economía Social y Solidaria: Una mirada desde Bolivia". Otra economía. Revista latinoamericana de economía social solidaria, 6 (11), pp. 159-170.

COLLIN, L. (2007): "Experiencias en torno al dinero alternativo, fortalezas y debilidades", Revista Pasos, 132, pp. 11-22.

CRUZ, A. (2011): "La acumulación solidaria. Los desafíos de la economía asociativa bajo la mundialización del capital", en III Congresso da rede de ITCPS e I simpósio internacional de extensão universitária e economia solidária, Porto Alegre, Brasil.

DUSSEL, E. (2014): 16 tesis de economía política. Una interpretación filosófica. México D.F., Siglo XXI.

DUSSEL, E. (2016): 14 tesis de ética. Hacia la esencia del pensamiento crítico. Ciudad de México, Editorial Trotta.

ECHEVERRÍA, B. (2017 [1986]): El discurso crítico de Marx. Ciudad de MéxiCO, FCE/ITACA.

ECHEVERRÍA, B. (2005) "Renta Tecnológica y Capitalismo Histórico", Mundo Siglo XXI, 2, pp. 17-20.

GARCÍA, A. (2015 [1994]): Forma valor y forma comunidad. Quito, IAEN/ Traficantes de sueños.

GUTIÉRREZ, R. (2009): Los ritmos de Pachakuti. Levantamiento y movilización en Bolivia (2000-2005). México D.F., Bajo Tierra Ed./BUAP.

GUTIÉRREZ R. y SALAZAR H. (2015): "Reproducción comunitaria de la vida. Pensando en la trans-formación en el presente". El Apantle. Revista de Estudios Comunitarios, 1, pp. 15-50

HERNANDO, A. (2018): La fantasía de la individualidad. Sobre la construcción sociohistórica del sujeto moderno. Madrid, Traficantes de sueños.

HINKELAMMERT, F. y MORA, H. (2013): Una economía para la vida. Preludio a una segunda crítica de la economía política. Morelia, UMSNH.

POLANYI, K. (2015 [1957]): La gran transformación. Los orígenes políticos y económicos de nuestro tiempo. México DF, FCE.

SABOURIN, E. (2011): "Teoria da reciprocidade e sócio-antropologia do desenvolvimento". Sociologias. 27, pp. 24-51.

SEMO, E. (2006): Historia económica de México. Vol. 01: los orígenes, de los cazadores y recolectoras a las sociedades tributarias $(22,000$ a. C. 1519 d. C.). México D.F., UNAM/Océano.

WOLF, E. (2001 [1998]): Figurar el poder. Ideologías de dominación y crisis. México D.F., CIESAS

VILLORO, L. (2010 [1992]): El pensamiento moderno. Filosofía del renacimiento. México D.F, Fondo de Cultura Económica. 